\title{
ATTRIBUTE 7 AND ASSESSING WRITTEN COMMUNICATION SKILLS IN ENGINEERING
}

\author{
Anne Parker ${ }^{1}$, Kathryn Marcynuk ${ }^{1}$ and Roger Graves ${ }^{2}$ \\ ${ }^{1}$ Design Engineering, University of Manitoba and ${ }^{2}$ University of Alberta \\ Anne.Parker@umanitoba.ca ; ummarcyk@cc.umanitoba.ca
}

\begin{abstract}
This paper will focus on Attribute 7, "Communication Skills" - and, specifically, on written assignments. This paper has grown out of two initiatives, one at my institution and one undertaken independently as part of a national study. For the faculty-wide initiative, we are preparing rubrics that can be used throughout the faculty as guidelines for attribute assessment in undergraduate Engineering courses. However, we have little information on Attribute 7; which courses, for example, target Attribute 7 and how is it assessed? What kinds of assignments are students being asked to complete? More broadly, what should we be teaching and assessing if we choose to target Attribute 7 in our outlines?

Interestingly, it is the independent national study that may help us in this endeavor. After collecting course outlines from all the Engineering departments, we can first determine which courses target Attribute 7 and then analyze the written course assignments according to 20 identifiable variables, such as length, genre and grading criteria. The challenge will be in calibrating Attribute 7 and our undergraduate program, including the undergraduate communication courses in our school that instantiate Attribute 7. In this paper, we will report on our progress thus far, both in the process of identifying the written assignments our students are being asked to do and in the development of facultywide rubrics.

Finally, although linking attributes to learning objectives and determining the levels of communicative competence can be very challenging, we hope to show that these two initiatives may help to make the tasks less daunting and more manageable for all the stakeholders in the education of our Engineering students.
\end{abstract}

Keywords: Attribute 7, communication skills, written assignments, rubrics, Engineering education

\subsection{INTRODUCTION}

The Canadian Engineering Accreditation Board (C.E.A.B.) introduced attributes and outcomes as standards to be met, not merely to standardize the curricula of the various Engineering schools, but also to encourage these schools to take a step back and reflect on the quality of the students we were graduating. Were these new graduates able to transition successfully to the world of the professional engineer, where the work can be multi-faceted and complex, and where the concomitant demands on the engineer can be equally challenging? Our industry partners would often say "no" - which was worrisome, to be sure - but the discussion would be anecdotal. Consequently, our Engineering school was one of many who decided that we needed some way to gauge just how design-ready our graduates were; we thought they were, but we lacked the evidence. Nor did we have any idea as to how proficient our graduates were in the communication of that engineering work.

As M. Davis has already noted, these "soft skills" are difficult to define and their success - or failure - is even harder to measure [1]. However, integrating communication into courses and into a program means it has the "same weight and attention" as any other outcome. Contrary to the "add-on" model where, for example, instructors from "English" are parachuted in as communication instructors - this practice-based model ensures a stronger performance (pp.42-43). Just as important, if not more so, "students perceive that professional communication is woven into their jobs and their employers' expectations" (43); they come to appreciate that communication is "equally important to engineering practice" [2, p. 1]. Such conclusions may all be true, but the possibility still exists, as Ford and Riley caution, that students continue to view the technical work as the "real" work [3, p. 80].

After our 2012 accreditation visit, the University of Manitoba set out to discover what the proficiency levels of our graduates might be. This initial drive for that information prompted us to develop a plan whereby we could continue to gather the data and successfully integrate these 12 C.E.A.B. attributes into the fabric of our Engineering education. At the same time, we wanted feedback from two important stakeholders: industry, as to how "ready" our graduates were, and the students themselves. The series of industry forums are helping us to gauge the first [4] while the faculty-wide initiative is helping us to determine the second [5].

This faculty-wide initiative has been engaged in developing rubrics that will help us to fulfill our pedagogical and professional goals; to define our expectations; to help us think about our performance in 
meeting these expectations; and to help us think about the performance levels of our students. Ultimately, these rubrics may well be the tools that we can use to communicate with all of our stakeholders, including students, alumni and industry partners. Thus, in the long term, we are trying to use these rubrics as "benchmark[s] for institutional improvement" and as tools to inform our pedagogy [6]. As Anson et al point out, "generic rubrics are said to unite faculty around common goals, terminology, and rhetorical perspectives" (p. 1).

We must, however, be cautious in applying them as standards that are not situated within the context of a particular discipline or even a particular course; otherwise, their usefulness may be compromised. Each rubric must be flexible enough for individual instructors to use effectively; in other words, to adapt it to the context in which it is to be used. That context will include the outcomes and attributes and expected competency levels envisioned by that individual instructor. In this important way, then, this first iteration is really a building block that we can use to develop future assessment tools that each of us can adapt to our needs.

To that end, the findings from another initiative, a national study that is investigating the kinds of written assignments our undergraduate students are being asked to write in a variety of contexts - including engineering ones - may offer some insight into what we need to be targeting in our rubrics. We can analyze these assignments according to 20 variables, including length, feedback provided, genre and grading criteria. In the case of our specific faculty, we can also tabulate how many courses target Attribute 7, "Communication Skills," and collate that information with the kinds of assignments these students write and the kinds of feedback they receive. One measure of a student's communicative competence, for example, will be reflected in the expected competency level for a particular written assignment, and this level can then be matched with the competency level defined in the rubric. In this important way, based on what each of these initiatives has to tell us about communicative competence and assessment, we may then begin to see what kinds of things we should be teaching and assessing if we target Attribute 7 in our outlines, including those for the undergraduate communication courses.

\subsection{THE WRITING ASSIGNMENT INITIATIVE}

As part of a larger, national study that is looking at the different kinds of writing assignments that students are being asked to write in a variety of undergraduate programs, this initiative has so far collected data from all the Engineering departments at the University of Manitoba: Civil, Electrical and Computer, Mechanical, Biosystems and Design Engineering. The study examines criteria such as assignment length; time to complete the assignment; the type of assignment (genre); feedback provisions within the assignment; and the frequency of assignments according to program year. Our objective is to promote discussion at the department and the faculty levels so that we can continue to fulfill our ongoing commitment to develop and improve our faculty's curriculum. On the one hand, this study will help us to tailor assignments that will help students learn how best to shape their writing so that it does indeed support the engineering work [7]. On the other hand, this kind of analysis can help us in our ongoing drive to meet the demands of the profession.

To date, we have analyzed 102 assignments given in 35 courses in the Department of Mechanical Engineering in the fall of 2012. Interestingly, most syllabi did not specify the requirements for each assignment, nor did the syllabi indicate whether the assignment even had a written component. Many of the assignments have been listed as "unclear" simply because no description of the assignment was included on the course syllabi. In those cases where "assignment" was listed, but without any further information, the assignments were coded as a written assignment only if the instructor identified A7 under learning outcomes.

While course length was mostly given as 13 weeks in length, no information as to how long students had to complete assignments was given; the completion dates for the written assignments were rarely, if ever, specified. Syllabi were likewise often unclear regarding the required length of an assignment, the content to be included (and evaluated) and the formatting requirements. Few specified which citation style (such as IEEE) was to be followed.

Almost half of the assignments listed in the syllabi gave no information about the genre of writing that students were being asked to produce; they were simply labeled as "assignments" (48/102 or $47 \%)$. However, the most frequent genre that was listed was the "report," followed by "proposals" (22/102 or 22\%) and "lab reports" $(16 / 102$ or $16 \%)$. Taken together, these various reports represent over half of all assignments. It's also worth noting that, in the Department of Mechanical Engineering, students must write at least one assignment for their courses while, on average, these students write three writing assignments per course throughout their undergraduate degree. In 3rd year, however, students average fewer than two assignments per course, a significant change from what we see in $2^{\text {nd }}$ and $4^{\text {th }}$ years. 
Table I: Average Number of Written Assignments in Each Program Year

\begin{tabular}{|l|l|l|l|l|}
\hline & $\begin{array}{l}\text { Year } \\
\mathbf{2}\end{array}$ & $\begin{array}{l}\text { Year } \\
\mathbf{3}\end{array}$ & $\begin{array}{l}\text { Year } \\
\mathbf{4}\end{array}$ & Total \\
\hline $\begin{array}{l}\text { \# of courses in } \\
\text { sample }\end{array}$ & 4 & 10 & 22 & 36 \\
\hline $\begin{array}{l}\text { Total \# of written } \\
\text { assignments }\end{array}$ & 16 & 18 & 68 & 102 \\
\hline $\begin{array}{l}\text { Average \# of } \\
\text { written } \\
\text { assignments per } \\
\text { course }\end{array}$ & 4 & 1.8 & 3.1 & 2.8 \\
\hline
\end{tabular}

Most assignments (60/76 or $79 \%$ ) asked students to comprehend (rephrase information) or apply knowledge (combine separate elements into a whole). The following table shows the competency level expected and the number of assignments that required it.

Table II: Expected Competency Level (A7)

\begin{tabular}{|l|l|}
\hline Level & \# of assignments \\
\hline 1 (knowledge) & 0 \\
\hline 2 (comprehension) & 16 \\
\hline 3 (application) & 44 \\
\hline 4 (analysis) & 10 \\
\hline 5 (synthesis) & 6 \\
\hline 6 (evaluation) & 0 \\
\hline
\end{tabular}

Therefore, any additional information was difficult to find because so few details would be given in the course syllabus. For example, we could not determine the relative length of any of the written assignments, nor was the audience specified - with the notable exception of one assignment that specified that the audience was not the instructor or students in the class. Very few syllabi mentioned how feedback would be provided; only lab reports did. Finally, only one course syllabus indicated the criteria that would be used to evaluate the assignment. These findings suggest a real need for course syllabi to clarify the course requirements in terms of the assignments. That is, we need to be as clear with respect to the kinds of assignments, what their requirements are and how they will be evaluated as we are when we delineate the attributes, outcomes and competency levels that we are targeting in our courses and in our programs.

\subsection{THE FACULTY-WIDE INITIATIVE: THE RUBRICS}

The Faculty of Engineering at the University of Manitoba opted to create rubrics for all the attributes so that, among other things, every instructor could use them as measures of student performance in a course and as indicators of content mastery. For each attribute, the benchmark - the level that we expect our students to achieve - is "competent." According to what we learned at the series of industry forums that we held, industry's expectations are similar [4]. However, although each focus area includes a series of indicators that can then be assessed according to whether the trait is "strong," "competent," "developing" or "needing work," the rubrics are descriptive; they offer a common ground for assessing these traits as they apply to a variety of scenarios. Even so, the value of these rubrics can be far-reaching.

For the instructor, as Boettger notes, the rubric counters the commonly held notion that students need only provide "what she likes" or "what he wants" in their papers; the rubrics clearly outline exactly what the expectations are and, at the same time, "educate students on how to meet those expectations" [8, p. 4]. As well, the various levels can be translated into numerical equivalents, a practice we follow in the technical communication rubrics as a way to silence the plaintive cries of "subjective" marking [9]. Indeed, this practice may be even more important in a communication course because numerical equivalents ensure that students see the "mark" for a trait, something they will ask for regardless. In this way, students can measure their progress in a course, but they also receive qualitative feedback that is useful for improving that particular characteristic [8, pp. 4-5].

But this initiative ultimately goes far beyond an exercise that tries to define competence. What this activity has forced us to do is consider all the things we as educators expect our students to be able to do, both as undergraduates and as future engineers. As well, we have had to consider our roles as educators, both in what we teach and how we teach it. Ultimately, as Anson and Dannels suggest, it is this kind of reflective thinking that is demanded by any program profile, such as the one the national study on written assignments is presently compiling [10]. In essence, the rubrics demand that we know exactly which topics should be covered in a course and, secondly, exactly what topic traits we intend to measure.

Two brief examples from the faculty-wide rubrics will have to suffice. For the "Attribute 7" rubric, "communication skills," we first outlined what we meant. Attribute 7 includes reading, writing, speaking and listening skills, all skills that competent engineers should be able to use when they must communicate complex concepts both to members of the profession and to the general public. Writing effective reports and effectively responding to instructions are also part of what we mean by "communication skills."

We began by first separating communication into written, oral and graphic communication, and then proceeded to establish some of the indicators that would help us to define what these entailed. For oral reports, 
for example, we (of course) included delivery, where we would measure such things as a speaker's tone, diction, volume, pacing and enunciation. But delivery also includes a "non-verbal" element; namely, the evidence of preparation that will be evinced by a speaker's reliance on prompts like slides or note cards; the control of posture and gestures; the speaker's body positioning in relation to the audience, such as behind a podium; the use of "stall" words like "um"; and the level of sustained eye contact that the speaker demonstrates as he or she gains a rapport with the audience.

As we determined the various levels, we first focused on what we would consider the "competent" level; that is, the level we expected our students to attain as they progress through the program and prepare for entry into the profession. For the "non-verbal delivery" indicator, for example, a "competent" speaker would do the following:

- Make eye contact

- Be easily heard

- Speak comfortably with some prompts (like note cards or slides)

- Move far enough away from the screen so that slides could be seen easily

- Appear comfortable

Alternatively, a "developing" speaker would have minor difficulties with the non-verbal delivery of a speech, while a presentation that "needed work" would have major difficulties with such things. Clearly, a "strong" non-verbal delivery of a talk would include sustained eye contact and show real polish.

In the case of written communication, one of the indicators is "genre and disciplinary conventions," an indicator that ties in with one of the variables being studied in the writing assignment initiative. In the rubric, we define this indicator as "familiarity with, understanding of, and use of the conventions," such as organization, formatting or even style choices, that are inherent within engineering genres and disciplines. Engineering genres would include proposals, progress reports, formal and informal reports, lab reports, and so on.

To be "competent," the student will demonstrate this kind of understanding, while a developing writer would only show "some" of this familiarity. In both these cases, the students would at least use - or attempt to use - these conventions. Alternatively, a report that "needed work" would show little or no understanding of this indicator while the "strong" writer shows a "sophisticated" understanding of issues related to genre and disciplinary conventions.

\subsection{CONCLUSION}

Thus, our goals in constructing the rubric were straightforward. At the faculty level, these rubrics indicate what is being measured. At the accreditation level, they give us an insight into whether - and how well - our students have been prepared for their profession. At the professorial level, they help us to gauge a student's progress and, ultimately, competency in the subject area. At a pedagogical level, however, this faculty-wide initiative is even more significant in that it has forced us to think deeply about what we teach in our courses as well as how we teach it. Implicit in this kind of activity is the need for us to consider what constitutes a "good engineer," on one level, and, on another level, to define several things associated with being a "good" or "competent" engineer, communicative competence among them.

However, as we all know, Attribute 7 can be an especially difficult attribute to define and measure. Even within the technical communication course, which is part of a relatively "young" field, this kind of definition is difficult. At the University of Manitoba, our Advisory Board for the course (comprised of E.I.T.s, young engineers and established professionals in industry) has helped us to determine those elements that need more emphasis, especially as to the genres we need to include, such as the briefing note. Nevertheless, as the national study of undergraduate writing assignments has illustrated, for our faculty-wide rubrics to work effectively, we need to spend more time outlining our expectations and defining such things as the length of our assignments, feedback provided, genre, and so on [11], [12], [13], [14].

In this important way, based on what each of these initiatives has to tell us about communicative competence and assessment, we may finally begin to see what kinds of things we should be teaching and assessing if we target Attribute 7 in our outlines, including those for the undergraduate communication courses. As we move forward, we can use the rubrics as guides to help us tailor our course assignments and syllabi to help us create a new paradigm of success.

\section{Acknowledgements}

The national study of undergraduate written assignments has been made possible by a grant from the Social Sciences and Humanities Research Council of Canada. The University of Manitoba study of faculty-wide rubrics has been made possible by the funding provided by the NSERC Chair in Design Engineering. The authors would also like to thank Jillian Seniuk Cicek, Nariman Sepehri and J.P. Burak for their valuable work on the rubrics, and Ken Ferens for his facilitation of the Industry Forum. 


\section{References}

[1] Marjorie T. Davis, "Assessing technical communication within Engineering contexts: Tutorial," IEEE Transactions on Professional Communication [Special Section on Assessment in Professional Communication], v. 53, n. 4, pp. 33-45, 2010

[2] Thomas Orr, "Assessment in professional communication: Editorial," IEEE Transactions on Professional Communication [Special Section on Assessment in Professional Communication], v. 53, n. 4, pp.1-3, 2010

[3] J.D. Ford and L.A. Riley, "Integrating communication and Engineering education: A look at curricula, courses, and support systems," Journal of Engineering Education, October issue, pp. 325-328, 2003.

[4] Ken Ferens, Jillian Seniuk Cicek, Nariman Sepehri, Witold Kinsner, J.P Burak, Anne Parker, Dean McNeill, Duglas Ruth, Ian Jeffrey, Norma Godavari, and Sandra Ingram, "Industry Forum III: Towards a common language," in Proc. CEEA Canadian Engineering Education Conf., CEEA14; Paper 035, Sean Maw and Marjan Eggermont (Eds.) (Canmore, AB; 8-11 June 2014), 6 pp., 2014.

[5] Jillian Seniuk Cicek, Sandra Ingram, Nariman Sepehri, J.P. Burak, Paul Labossiere, Danny Mann, Douglas Ruth, Anne Parker, Ken Ferens, Norma Godavari, and Jan Oleszkiewicz, "Rubrics as a vehicle to define the 12 CEAB graduate attributes, determine graduate competencies, and develop a common language for Engineering stakeholders," Proc. CEEA Canadian Engineering Education Conf., CEEA14; Paper 031, Sean Maw and Marjan Eggermont (Eds.) (Canmore, AB; 8-11 June 2014), 6 pp., 2014.

[6] Chris. M. Anson, Deanna P. Dannels, Pamela Flash, and Amy L. Housley Gaffney, "Big rubrics and weird genres: The futility of using generic assessment tools across diverse instructional contexts," Journal of Writing Assessment," v.5, issue 1 (January), 16 pp., 2012.

[7] Marie C. Paretti, "Teaching communication in Capstone Design: The role of the instructor in situated learning," Journal of Engineering Education, v.97, no.4, pp. 491-503, 2008.

[8] Ryan K. Boettger, "Rubric use in technical communication: Exploring the process of creating valid and reliable assessment tools," IEEE Transactions on Professional Communication, [Special Section on Assessment in Professional Communication], v. 53, n. 4, pp. 4-17, 2010.

[9] Anne Parker and Aidan Topping, "Designing rubrics for communication courses in Engineering: A work in progress," Proc. CEEA Canadian Engineering Education Conf., CEEA13; Paper 143 (Montreal, QC; 17-20 June 2013), 6 pp., 2013.

[10] Chris A. Anson and Deanna Dannels. (2009, Dec.). "Profiling programs: Formative uses of departmental consultations in the assessment of communication across the curriculum." Across the Disciplines: A Journal of Language,
Learning and Academic Writing [Online], 6 [Special Issue on Writing Across the Curriculum and Assessment], pp. 1-16. Available:

http://wac.colostate.edu/atd/assessment/anson dannels.cfm [May 22, 2012].

[11] Roger Graves, Theresa Hyland and Boba Samuels, "Undergraduate writing assignments: An analysis of syllabi at one Canadian college," Written Communication, v.27, no.3 (July), pp. 293-317, 2010.

[12] Roger Graves, "Five strategies to improve writing in your courses," University Affairs (January 15), 2014. Online: http://www.universityaffairs.ca/five-strategies-to-improvewriting-in-your-courses.aspx

[13] Roger Graves, "Why students struggle with writing: What to do about it," University Affairs, v.54, n.8 (October 2013), p. 37.

[14] Roger Graves, "Genre by numbers: A data-driven description of academic discourse," Conference on College Composition and Communication, Indianapolis IN, March 22, 2014. Available: http://prezi.com/sao91camvqg6/genre-by-numbers/ 